\title{
Os professores e a escola: lidando com a diversidade étnica
}

\author{
Maria Aparecida Clemêncio
}

Este texto é um convite à reflexão, com o propósito de instigar a curiosidade dos professores, incluindo os de arte, a pensar e trazer para o cotidiano da sala de aula, o respeito e atenção com grupos étnicos não hegemônicos, neste caso específico, dos afrodescendentes. Promover o debate sobre a importância de se incluir nos cursos de formacão de professores, o estudo sobre a diversidade étnica é uma de nossas preocupações. Focalizaremos as questões da diversidade, a partir da etnia afrodescendente, para compreendermos e valorizarmos as questões da diferença étnica/racial na educação. Nesta perspectiva, apontamos limitações e possibilidades nas práticas pedagógicas na relação com as identidades diferenciadas, no sentido de fomentar e estimular os professores a refletirem sobre as diferenças étnicas na escola.

Num passado recente, tínhamos uma visão bastante restrita de cultura: o de instrução escolar para as classes populares e de belas artes, artes plásticas, dança e literatura para a classe dominante (Chauí, 1999). Esta noção de cultura ainda não foi de todo vencida, ela permanece no consciente coletivo das pessoas o que de certa forma as impede de perceber o seu sentido maior e conseqüentemente as suas diferentes manifestações. A cultura que enfatizaremos abrange um sentido antropológico, entendido como construção histórica, ultrapassa as leis físicas ou biológicas, e é um produto coletivo da vida humana. Esta noção de cultura traduz-se num sentido mais amplo, implicando uma outra responsabilidade, a discussão sobre a pluralidade e diversidade cultural entre os povos.

Algumas pesquisas de investigação desta 
questão na educação têm sido desenvolvidas, das quais podemos citar Gomes (1996), Silva (1993, 1997) e Candau (1996, 2003). Apontam investigações em torno da formação de professores/as, num contínuo crescente nos últimos dez anos. A ênfase tem sido no Ensino Fundamental, mais precisamente em torno dos professores/as de $1^{\text {a }}$ a $4^{\text {a }}$ série, embora haja também manifestações de $5^{\mathrm{a}}$ a $8^{\mathrm{a}}$ série e no ensino médio. Esses trabalhos têm procurado identificar pontos críticos na formação desses(as) professores(as), assim como apontar caminhos para a introdução de mudanças que favoreçam uma formação mais consciente desses profissionais. Nesta perspectiva, este texto busca suscitar o debate sobre a importância de se incluir nos cursos de formação de professores o estudo sobre a diversidade cultural e das diferentes identidades étnicas. Focalizaremos a diversidade como pontochave para compreendermos e valorizarmos as questões da diferença étnica na educação. Destacaremos o afrodescendente como preocupação maior, por ser esta a etnia que exerce considerável destaque na influência e contribuição para a construção do caldeirão cultural que constitui a sociedade brasileira. Nesse sentido, apontamos limitações e possibilidades nas práticas pedagógicas, na relação com as identidades diferenciadas. A escola, no dizer de Candau (2003), é espaço de representação de manifestações de discriminações de todo tipo. A cultura da escola está imbuída pela igualdade, baseada por um caráter monocultural; em geral,a escola lida mal com as diferenças, tende a silenciá-las ou neutralizá-las.

O ensino de arte, pelo seu dinamismo, seja na música, nas artes plásticas ou nas artes cênicas, pode contribuir com muita propriedade no trato com a diversidade. A arte lida com atitude e a atitude têm a capacidade de transformação; neste 
caso, através da arte podemos eqüalizar diferenças sociais, de idade, de gênero, sobretudo diferenças culturais e étnicas. 0 interesse maior é levar os professores a perceberem, na escola e nas propostas pedagógicas dos cursos, que histórias culturais estão sendo produzidas, como se constróem as identidades culturais e quais as fronteiras étnicas/raciais entre os grupos sociais que interagem na escola. Com essa prática, se criam possibilidades de lidar com o outro, e conseqüentemente, com as diferenças. São preocupações que vêm de encontro a como a diversidade se apresenta para os educadores em virtude de não podermos ignorar, neste século, as questões de cultura, raça, etnia, identidade, poder, conhecimento e ética no trabalho escolar.

\section{Sobre o conceito de cultura}

Do ponto de vista antropológico, segundo Laraia (1996) a primeira definição de cultura foi proposta por Tylor em fins do século XVIII. Através da união de dois termos kultur, que simbolizava todos os aspectos espirituais de uma comunidade e civilization, realizações materiais de um povo, chegando ao termo culture em inglês. "Em 1871 Tylor define cultura como sendo todo o comportamento aprendido, tudo aquilo que independe de uma transmissão genética, como diríamos hoje" (Laraia,1996, p. 28).

A partir do conceito de Tylor, outros conceitos de cultura foram se constituindo. $\mathrm{Na}$ antropologia atual vamos encontrar diversos conceitos por exemplo, Santos (1994, p.44) afirma que cultura "diz respeito a tudo aquilo que caracteriza a existência social de um povo ou nação, ou então de grupos no interior de uma sociedade". Acrescenta ainda que:

Cultura é uma dimensão do processo 
social, da vida e de uma sociedade. Não diz respeito apenas a um conjunto de práticas e concepções como por exemplo se poderia dizer da arte. Não é apenas uma parte da vida social como por exemplo se poderia falar da religião. Não se pode dizer que cultura seja algo independente da vida social, algo que nada tenha a ver com a realidade onde existe. Entendida dessa forma, cultura diz respeito a todos os aspectos da vida social, e não se pode dizer que ela exista em alguns contextos e não em outros. Cultura é uma construção histórica, seja como concepção, seja como dimensão do processo social é uma construção histórica é um produto coletivo da vida humana (SANTOS, 1994, p.44).

Atualmente o conceito de cultura supera a concepção universal desta, ou seja, a de que todos grupos e indivíduos - possuam uma mesma cultura. A cultura está ligada diretamente à diversidade, às diferentes manifestações dos povos. Para Candau,

a cultura aparece "como um estruturante profundo no cotidiano de todo grupo social e se expressa em modos de agir, relacionar-se, interpretar e atribuir sentido, celebrar (...), quando ignorada ou reprimida, conseqüências muitas vezes de ampla repercussão se manifestam, $a$ curto ou longo prazo, de modo imprevisível e, muitas vezes dramático (1996, p.96).

1 Petronilha B. G. e Silva, docente do departamento de metodologia de Ensino da Universidade Federal de São Carlos/SP Seminário Educação e diferenciação Cultural promovido pela Apocs, Cedes (palestra não publicada). 
Podemos salientar ainda o papel da cultura que, na opinião de Silva', é "o de codificar o mundo, ou melhor dizendo, a cultura contém a trama de signos com que as pessoas significam os objetos, os acontecimentos, as situações e as outras pessoas que as rodeiam. Cada indivíduo, de posse do código, se movimenta facilmente no universo de sua cultura, age na certeza de ter seu comportamento confirmado pelo grupo".

Por isso, a imposição de uma só cultura, além de quebrar os códigos identitários, também interfere no sentido de orientação das pessoas. Não podemos continuar permitindo que o "diferente", o "outro" tenha que se autonegar ou arremedar a cultura de quem detêm o poder de mandar e de estabelecer o que é correto. A escola é o espaço onde as classes e grupos desprestigiados pela sociedade iniciam um momento de ruptura com o seu modo de viver, de aprender, de significar. É também o espaço em que estas classes e grupos creditam a possibilidade de ascensão cultural, social e econômica. Também é na escola que vemos, em maior ou menor grau, a assimilação de um modelo cultural tido como superior. E é justamente essa postura monocultural e excludente que gostaríamos que fosse revista em nossas práticas no interior das instituições de ensino, seja ela de Ensino Fundamental, Médio ou Superior.

Nesse sentido é que diferentes grupos sociais vêm lutando atualmente, pelo reconhecimento cultural. Busca-se um novo progresso social, luta-se contra a exploração/exclusão de grupos culturais e étnicos, pela superação da discriminação, da opressão e das desigualdades entre os povos. Através da cultura tenta-se garantir as diferentes identidades; nesse universo de diversidades.

\section{Etnia e Raça?}


As teorias sobre a etnia e a etnicidade, assim como sobre as relações interétnicas, tiveram início na França em fins da década de 60 e mais precisamente na década de $70 \mathrm{com}$ a sociologia. Frederik Barth em 1969 escreve sobre a organização social da diferença de cultura. Substitui a visão estática da identidade étnica por uma concepção dinâmica. Barth entendeu muito bem e fez entender que essa identidade, como qualquer outra identidade coletiva (e assim também a identidade pessoal de cada um), é construída e transformada na interação de grupos sociais através de processos de exclusão e inclusão que estabelecem limites entre tais grupos, definindo os que interagem ou não. Baseado nessa premissa, um grupo étnico designa uma população que: “ $a$ ) se perpetua principalmente por meios biológicos; b) partilha valores culturais num todo explícito; c) compõe um campo de comunicação e interação; d) tem um grupo de membros que se identifica e é identificado por outros como constituinte de uma categoria distinguível de outras categorias da mesma ordem."

A noção de etnia está associada, geralmente, numa relação de oposição à raça. Enquanto a noção de raça ${ }^{2}$ vincula-se à sua base biológica, o que não quer dizer diferenciação entre seres humanos, porque dizer que as raças biológicas serviriam para diferenciar os seres humanos seria preservação do racismo. Por isso Appiah (1997) reafirma dizendo que sem sombra de dúvidas, os seres humanos descendem de uma população original e provavelmente da África, distribuindo-se a partir daí e povoando o mundo. A noção de etnia estaria por sua vez vinculada a uma base estritamente

2 A palavra raça, conforme Munanga, surge no século XVI, originário do italiano "razza", oriundo do latim ratio, que significa sorte, categoria, espécie, inicialmente usado na botânnica para classificar as espécies animais e vegetais. Posteriormente, no latim medieval, passou a designar descendência, linhagem, grupo de pessoas com um ancestral comum. 
sócio-cultural, histórica e psicológica, daí estar sempre associada a grupo. Logo, um grupo populacional, dito "branco", "negro" ou "amarelo", pode conter no seu conjunto, diversas etnias. Podemos dizer que alguma etnias constituíam sozinhas nações, como o caso de vários indígenas brasileiros; de afriacanos, asiáticos, dentre outros, que foram ou são etnias nações.

Meyer (1998), apropriando-se do conceito de Stolke, nos diz que o termo etnia assume um sentido mais generalizado no pós - guerra por repugnância ética ao sentido biológico das doutrinas racistas dirigido às raças. 0 que significa dizer que a etnia serviria para distinguir o fato simbólico / social, mais ligado à cultura, do natural, mais ligado à raça. Porém, de certa forma, estes conceitos passaram a ser quase sinônimos no entendimento coletivo. Cultura, etnia ou raça são conceitos permeados por implicações políticas e teóricas.

No entanto, poderíamos dizer que a raça tem sido utilizada por alguns teóricos como categoria discursiva e não no sentido biológico. Porém, não é como categoria discursiva que o movimento negro apropria-se do conceito de raça. O conteúdo discursivo dessa categoria, além de funcionar como discriminatório em relação aos negros, contribui com os conceitos perversos e preconceituosos, diminuem a auto-estima da criança negra. Assim, ao apropriar-se do conceito de raça, o movimento negro o tem como categoria sócio-política, na sua metamorfose, transformando-o em bandeira de reivindicação política, contribuindo para a organização dos negros, revelando e combatendo as práticas racistas camufladas de nossa sociedade. Mesmo que as reivindicações por políticas em prol dos negros estejam por se constituir, este movimento tem contribuído para sensibilizar alguns educadores. 
A exemplo disso temos Silva (1995) e Sacristán (1995) que têm denunciado o silêncio e a omissão da escola na valorização das diferenças étnicas e culturais. O preconceito e a discriminação das minorias sociais, assim como a invisibilidade de outras, parecem ainda fazer parte dos processos curriculares e de formação em nossas escolas.

Baseados nisso é que evidenciamos a questão da cultura étnica na escola. Estudos e pesquisas de Silva (1993) e Gomes (1996) vêm demonstrando que a cultura de origem africana na escola tem sido, de certa forma silenciada, quando não excluída dos processos de formação de nossos professores(as), conseqüentemente impossibilitando que as crianças negras possam reafirmar suas identidades culturais. A escola tem um papel social e, se o contexto educacional é um contexto de diversidades, então temos que pensar que as diferentes identidades étnicas devem ser consideradas, garantindo às diferentes identidades etno-raciais o exercício da cidadania.

0 povo negro, onde quer que esteja, entre culturas africanas ou outras, apesar dos 500 anos de submissão ao Ocidente que o colonizou, à razão, ainda expressa a vida com o corpo inteiro. A pele negra não o deixou esquecer que é o corpo, antes de mais nada, e não apenas com bons sentimentos e perfeitos raciocínios, que descobrimos o mundo, as outras pessoas e o que eles pensam de nós. Os corpos negros põem à vista, no gingado, no gesto, na fala, nas indumentárias, o raciocínio, as emoções, as intuições, a história de diferentes grupos étnicos, de diferentes nações africanas, reunidos 
compulsoriamente no Brasil, nas Américas, como principal instrumento do sistema econômico-social escravagista (SILVA, 1997, p.40).

Torna-se urgente que profissionais da educação, das artes e das mais diferentes áreas, devam incluir em seus estudos e práticas, as diferentes matrizes culturais e étnicas que constituem a nação brasileira: a indígena, a africana e a européia ${ }^{3}$, torna-se um compromisso a que não mais podemos nos furtar. Quando dizemos incluir, não estamos falando de lembrar do dia do índio, do 13 de maio, ou do 20 de novembro; a inclusão deve ser cotidiana, explícita nos conteúdos e práticas, permeando todo currículo escolar, estar presente no dia a dia da escola.

\section{Construindo Identidade}

Falar de identidade não é uma tarefa fácil, devido às suas inúmeras abordagens. Porém, o que percebemos é que diferentes culturas e grupos étnicos habitando o mesmo espaço territorial precisam ter suas identidades preservadas. Há que se garantir o direito à diferença. Buscamos combinar diversidade e igualdade, a igualdade na diferença, longe da diferença marcada pela superioridade de uns em detrimento da inferioridade de outros, mas a combinação da igualdade com diversidade. Em que sentido? Reservando a liberdade de expressão dos valores étnicos e culturais, das crenças, dos códigos identitários dos diferentes grupos étnico / raciais, presentes na cultura nacional.

3 Ao falar em índios, nos referimos a diferentes nações, com distintas concepções e expressões: guaranis, caigangues, charruas, curumins, potiguaras, terenas, bororos, etc...Mencionando europeus, estamos falando de : portugueses, italianos, alemães, franceses, holandeses, etc. Citando africanos, mesmo que as contingências da dilacerante experiência de ser escravo tenham varrido da memória, estamos fazendo referência aos gegês, nagôs, yorubás, quimbundos, molungos, minas, etc. 
Falaremos aqui da formação de identidade afrodescendente, por termos orientado nossos estudos e pesquisas nesse grupo e, por entendermos que este grupo é consideravelmente expressivo em nossas escolas públicas, e por recair sobre ele as mais diferentes manifestações de discriminação e preconceitos, que a escola ainda não tem dado conta de trabalhar. No entanto, esta escolha não impede de tratarmos da formação de identidade de qualquer outro grupo étnico.

Ter uma identidade hoje,seja ela cultural ou étnica, implica perceber como essas identidades vêm sendo construídas. Que mecanismos interferem no sentido de querer ou não pertencer a um determinado grupo. Que aspectos são mais determinantes na formação das identidades, os apelos externos, educação, mídia, os preconceitos, enfim, o que afeta os indivíduos na construção de suas identidades.

A identidade social foi definida por Tajfel (1982) como o auto-conceito individual, formado a partir das interações grupais, envolvendo sentimentos de pertença emocional e de valor. 0 interessante a se considerar sobre identidade é que ela se constrói na relação com os outros, num contexto histórico e cultural. Pessoas ou grupos identificam-se ou desenvolvem sentimentos de pertença social ou cultural quando se sentem confirmados nesse grupo, ou seja, o sentimento de identidade desenvolve-se a partir de estímulos valorativos, de auto-afirmação e visibilidade grupal.

Goffman (1988), classificou a identidade em social, pessoal e do eu. Para ele, a identidade social pode ser real, pelos atributos que a pessoa possa possuir; e virtual, pelas características e o caráter que imputamos a um indivíduo, segundo aquilo que achamos que ele deveria ser. A identidade pessoal refere-se aos dados de identificação do sujeito, que 
permite que este se distinga de outros, como por exemplo: fotos, certidão de nascimento, Carteira de identidade, etc. E a identidade do eu estaria mais ligada à questão do caráter dos sujeitos, resultado de suas várias experiências sociais.

No caso da identidade étnica, ela é adquirida num contexto histórico e cultural, na relação entre um e o outro, isto é, no respeito as suas diferenças. Com relação ao respeito e consideração à identidade étnica do afrodescendente, esta tem uma especificidade: o retorno às tradições africanas, à memória coletiva a que, em virtude da diáspora ${ }^{4}$, os desenraizou de seu espaço de origem. Neste caso, para os afrodescendentes, há que reconstituir uma descendência que the foi negada historicamente. Muito de sua ancestralidade precisa ser apropriada por ele e pela sociedade.

Quero dizer que para reconhecer-se negro é preciso conhecer os fundamentos culturais africanos, o que o identifica. Sua religião, sua língua, seu lugar de origem, que para os negros tornou-se difícil, à medida que o pouco de sua ancestralidade é visto como "menos" pela sociedade brasileira, logo relegado à exclusão. Além disto, Kabengele (1999), comenta que a forma de racismo universalista brasileiro, que promoveu a mestiçagem cultural, não delimita nitidamente o espaço do jogo de todas as identidades. Como promover sua identidade, se ela não está separada das demais? Localiza-se aí a dificuldade em construir uma identidade singular que não possa misturar-se com a identidade dos outros. Neste sentido, Gomes acrescenta:

Construir uma identidade étnica positiva em uma sociedade que ensina ao negro, desde cedo, que para ser aceito é preciso igualar-se ao outro é

4 Diáspora é entendida pela dispersão de povos africanos, em decorrência do tráfico negreiro da África para as Américas. 


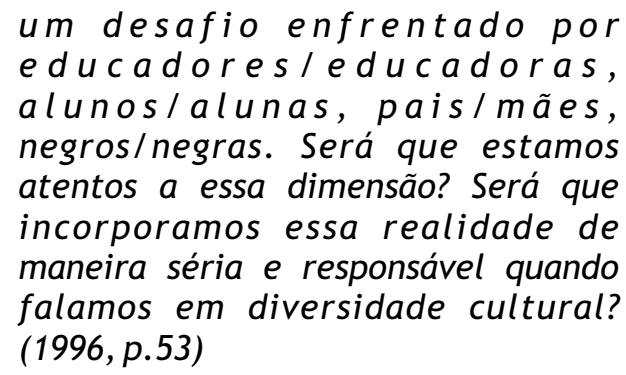

Este tem sido um movimento de busca, e tem resultado em algumas conquistas. A identidade étnica não nasce com as pessoas. Ela se constrói na relação entre os grupos. No caso dos afrodescendentes, busca-se o resgate de uma identidade étnica positiva, partindo das histórias de resistência do povo afrodescendente, contrapostas à historiografia oficial dos "vencedores". Nesta relação, são reafirmadas as diferenças internas do grupo e com ela, a reivindicação por direitos, onde se constrói um sujeito político.

Compreender a diversidade e respeitar as identidades na escola passa por entender que o ensinar e o aprender vão além dos conteúdos, da avaliação e das práticas disciplinares. É preciso compreender que os professores(as) são sujeitos culturais, carregam histórias, valores, preconceitos, possuem uma identidade e seus valores, sua maneira de ver e de relacionar-se com o mundo interfere no seu fazer pedagógico e no seu olhar para com o outro.

\section{Ambiente escolar, diversidade e formação de professores}

Em uma sociedade multicultural e pluriétnica como a nossa não podemos ignorar esta diversidade no contexto escolar. Nesse contexto, percebemos pessoas de diferentes coletividades, culturas e etnias que possuem compreensões diversas do 
mundo, da vida, e das relações sociais, dotadas de símbolos, rituais, crenças e valores diferenciados. Entretanto, essa diversidade existente na escola, muitas vezes acaba sendo camuflada, em virtude do modelo educacional vigente, que universaliza a cultura, ou seja, adota um modelo cultural único, geralmente o do grupo social hegemônico, impedindo que as demais culturas possam ser incluídas nos processos de ensino. No dizer de Costa, a cultura européia se impôs na escola e fortaleceu sua identidade:

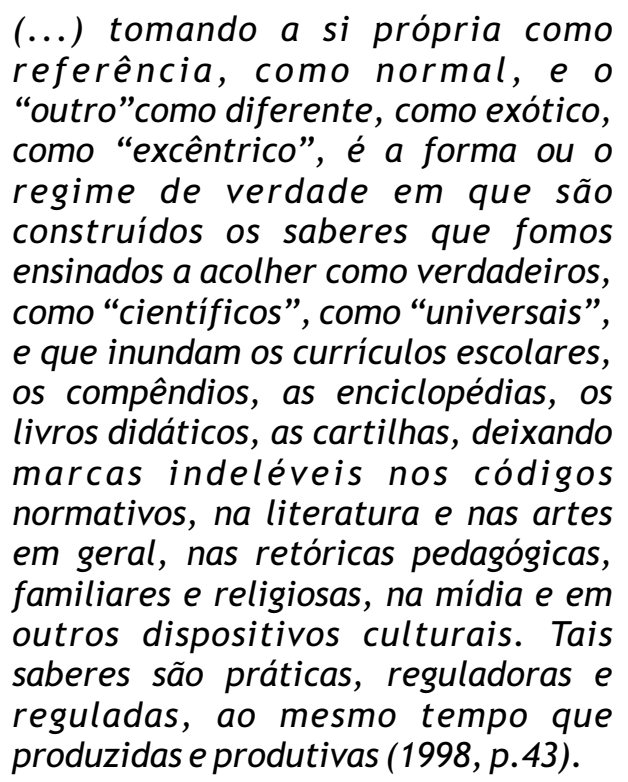

Essa prática escolar, ainda que há muito tenha sido diagnosticada e apontada por integrantes do movimento negro, só agora vem sendo questionada. As lutas contra a exclusão das demais culturas na escola advêm de integrantes de movimentos sociais, de alguns pesquisadores e da pressão de educadores contemporâneos que têm clamado por mudanças. São iniciativas dos estudos culturais que adentram a educação e o contexto de formação de 
nossos professores, "desafiam a suposta inocência ideológica e institucional dos(as) educadores(as) convencionais ao argumentar que os(as) professores(as) sempre trabalham e falam no interior de relações histórica e socialmente determinadas de poder" (Giroux, 1995). 0 autor chama a atenção para aqueles educadores contemporâneos que ainda baseiam-se na função integradora da escola como a homogenizadora de comportamento, inibindo criatividade, impossibilitando sua convivência com o diferente. Essa faceta do educador está diretamente ligada ao modelo universalizante da educação, o que supõe noções fixas de identidade cultural e nacional.

A escola, enquanto instituição social, passa a ser vista também como espaço de produção / reprodução / transformação de nossas heranças culturais e de integração dos diversos grupos sociais presentes em nossa sociedade. A valorização das diversas identidades culturais, de suas particularidades e contribuições específicas na construção do país, passa a ser exigida na escola, o que supõe considerar todas as pessoas e grupos como sujeitos culturais, com direito à criação, memória e participação cultural.

Através desse reconhecimento objetiva-se transformar a escola num espaço cultural onde se valorize a cultura dos "outros", dos considerados diferentes: negros, índios, mulheres, homossexuais, pessoas com história de deficiência, dentre outros, que se diferenciam do hegemônico cultural. Esse reconhecimento busca uma formação que respeite as diferentes identidades culturais de etnia / raça. Que supere a noção de identidade nacional amplamente definida pela transmissão da cultura tradicional, que tem sido cultura de exclusão, que tem ignorado as múltiplas narrativas, histórias e vozes de grupos culturais politicamente subordinados. Nesse caso, nos apropriando das idéias de Romão: 
a primeira atitude a ser tomada pela escola e pelos educadores é a de compreender os alunos como seres individuais que pertencem a culturas coletivas. Ou seja, um aluno não é igual ao outro. Nem mesmo aqueles que se parecem iguais. A segunda atitude, é compreender esta individualidade como parte de uma coletividade, de um grupo cultural, racial, étnico, econômico, regional, etc. Neste aspecto é importante considerar que algumas vezes percebemos equívocos quando tentamos trabalhar as diferenças étnico-culturais em sala de aula. Costumamos dizer que vamos estudar a cultura dos italianos, alemães, polonoses, japoneses dificilmente falamos chineses -, dos índios ( e não dizemos quais) e dos negros. (2001, $p$. 10)

Nesta perspectiva, como podemos tornar centrais, em nossos processos de construção e apreensão do conhecimento, a valorização das diferentes identidades? Como essa diversidade interfere nos processos de socialização e construção de valores identitários culturais e étnicos? As posturas adotadas têm sido no sentido da exclusão, inclusão ou reconhecimento dos diferentes? São questionamentos que nos fazem refletir sobre a escola como espaço importante de aprendizagens específicas e diferenciadas que muitas vezes não são oportunizadas em outros espaços. De outra forma, para Meyer (1998, p.80), "tem proporcionado um espaço narrativo e privilegiado para alguns enquanto produz / reforça a desigualdade e subordinação de outros".

Assim, cursos e currículos de formação de professores(as) constituem uma instância crucial 
de formação de sujeitos que estarão diretamente implicados no processo de produção, posicionamento e deslocamento das fronteiras e identidades culturais no âmbito dos diferentes grupos sociais (Meyer, 1998).

Nesse sentido, na visão de Arroyo (1996b) a escola assume uma função mais plural, adquire novas dimensões que vão além da função de ensinar as primeiras letras, as primeiras contas, as noções elementares de ciências e das artes.

A escola então deve estar atenta aos "movimentos" advindos da sociedade como os da atualidade - de globalização, neoliberalismo, mercado comum e "multiculturalismo", no sentido de ter um projeto educativo firme que oriente o seu fazer pedagógico. 0 que deve "(...) vincular-se à luta pelos direitos, com o movimento civilizatório, humanizador, cultural, e não apenas com as demandas do mercado. Deve imprimir propostas de qualidade social e cultural que busque a construção de sujeitos cada vez mais plenos de direitos" (Arroyo 1996b, p.169).

Dessa forma, vinculará o conhecimento nela produzido com a cultura, a socialização e as diferentes identidades presentes dentro e fora de seu contexto. Ainda que a cultura não se faça central na formação dos profissionais da educação, das artes, dentre outros, ao que define Arroyo (1996b), os cursos de pedagogia licenciatura e de magistério têm nos fornecido pouca informação teórica que permita atender aos complexos vínculos entre cultura e os processos de aprender e ensinar, extremamente delicados, perpassados pela cultura de quem ensina e de quem aprende. Ensinar não pode estar baseado simplesmente na tarefa entre quem ensina e o outro que aprende; a tarefa educativa deve estar compreendida entre dois ou mais sujeitos sócio-culturais que carregam consigo histórias, identidades e etnias que precisam 
ser interpretadas e que thes dêem novos significados.

Há que se fazer uma leitura crítica e contextualizada de como estão sendo formados nossos(as) professores(as), que conhecimentos estão adquirindo, em que condições estão sendo preparados(as) e quais os instrumentos de construção / manutenção / transformação sóciocultural de que vão dispor na escola. É uma tarefa eficaz no trato com a diversidade, se pensarmos que os(as) professores(as) estão na condição de produção / reprodução dos discursos e práticas na escola e que nestas estão implicadas sua cultura, sua etnia e suas múltiplas identidades.

\section{Referências Bibliográficas}

ARROYO, Miguel G. Assumir nossa diversidade cultural. Revista de Educação AE,v. 25,n.98, jan.mar.1996

. Prática pedagógica e Currículo.VIII

Endipe, Florianópolis, 1996b.

APPIAH, kwame Anthony. AÁfrica na Filosofia da Cultura. Rio de Janeiro: Contraponto, 1997.

CANDAU, Vera Maria. Pluralismo Cultural, Cotidiano Escolar e Formação de Professores. Anais Conferência, Simpósios, Mesas Redondas. Volume II,NUP/CED/UFSC. Florianópolis, 1996.

Somos todos iguais? Escola, discriminação e educação em direitos humanos. Rio de Janeiro : DP\&A, 2003.

COSTA, Marisa Vorraber. Currículo e política cultural. COSTA, Marisa Vorraber (org. ). O currículo nos limiares do contemporâneo. Rio de Janeiro: DP\&A, 1998.

CHAUÍ, Marilena. Cidadania Cultural. Novamérica, Pluralismo Cultural, n.82, junho, 1999.

FISCHMANN, Roseli. Consciência Mundial, Educação e Pluralidade Cultural: fundamentos da cultura da paz. Pátio: Revista Pedagógica. V.2 , n.6, p.49, .

GIROUX, Henry A. Praticando Estudos Culturais nas Faculdades de Educação. Alienígenas na Sala de Aula. Petrópolis, Rio Janeiro: Vozes, 1995.

GOFFMAN, Erving. Estigma: Notas sobre a Manipulação da Identidade Deteriorada. Rio Janeiro: Guanabara Koogan 
S.A. , 1988.

GOMES, Nilma Lino. Escola Identidade Étnica e Alteridade. Revista de Educação - AEC v. 25, n. 98.

GONÇALVES, Luiz Alberto Oliveira. O Jogo das diferenças: o multiculturalismo e seus contextos. Belo Horizonte: Autêntica, 1998.

KABENGELE, Munanga. Mestiçagem e identidade afrobrasileira. Cadernos PENESB, Niterói: Intertexto, 1999.

LARAIA, Roque de Barros. Cultura um conceito Antropológico. Rio de Janeiro: Zahar, 1996.

MEYER, Dagmar Estermann. Etnia, Raça e nação: Currículo e a Construção de Fronteiras e posições Sociais.

O Currículo nos limites do contemporâneo, Marisa Vorraber Costa, (org), Rio de Janeiro: DP\&A, 1998.

MUNANGA, Kabengele (org.). Estratégias e Políticas de Combate à Discriminação Racial.São Paulo.Edusp: 1996.p.177

OLIVEIRA, Roberto Cardoso de. Identidade, etnia e estrutura social. São Paulo: Pioneira, 1976.

ROMÃo, Jeruse. Por uma educação que promova a AutoEstima da Criança Negra. Brasília: Ministério da Justiça, Secretaria de Estado dos Direitos Humanos, 2001.

SANTOS, José Luiz dos. O que é Cultura. São Paulo: Brasiliense, 1994.

SILVA Tomaz Tadeu da (org.). Alienígenas na Sala de Aula.Petrópolis, Rio de Janeiro: Vozes, 1995.

SILVA, Petronilha Beatriz Gonçalvez e. Diversidade Étnico-Cultural e Currículos Escolares Dilemas e Possibilidades. Cadernos CEDES, São Paulo,1993.

- Vamos Acertar os Passos?

Referências Afro-Brasileiras para os Sistemas de Ensino. As Idéias Racistas, os Negros e a Educação. Série Pensamento Negro em Educação, v. 1, Florianópolis 1997. TAJFEL, Henri. "Categorização social, identidade social e comparação social”. H. Tajfel. Grupos Humanos $e$ categorias.Tradução de Lígia Amâncio. Lisboa: Livros Horizonte, Vol. I,1982.

SACRISTÁN, Gimeno J. Currículo e Diversidade Cultural. Territórios Contestados: o currículo e os novos mapas culturais. Petrópolis, Rio de Janeiro: Vozes, 1995.

SANTOMÉ, Turjo Torres . As Culturas Negadas e Silenciadas no Currículo. Alienígenas na_Sala de Aula. Petrópolis, Rio de Janeiro: Vozes, 1995. 